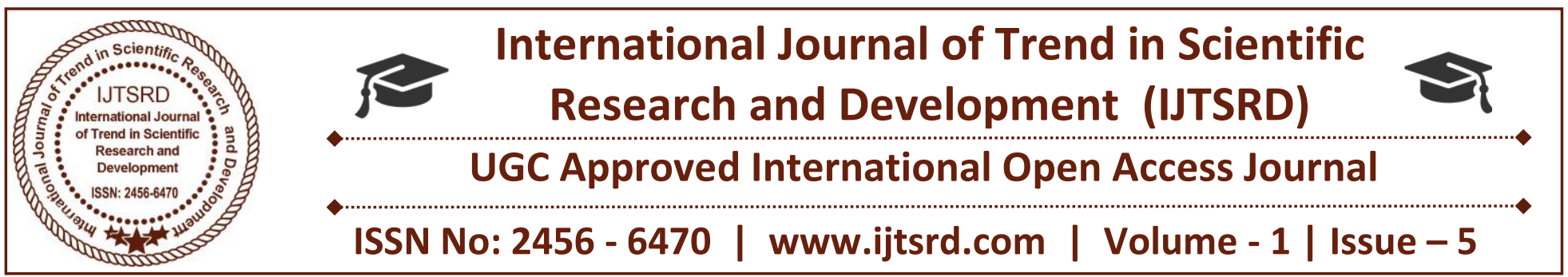

\title{
Compressive Strength of Conventional Concrete using E waste
}

\author{
Anil kumar Sharma \\ M.tech scholar, Jagannath University, \\ Jaipur, Rajasthan, India
}

\author{
Dr. Bharat Nagar \\ Head of Department, Civil Engineering, \\ Jagannath University, Jaipur, Rajasthan, India
}

\begin{abstract}
The Waste materials Utilization of construction industry by-products is a sustainable solution to ecological and environmental problems. Use of such waste materials makes their re utilization in cementconcrete, other construction materials, and also the cost of cement and concrete manufacturing is reduces. Other indirect benefits of e-waste include reduction in landfill cost, saving energy and reduction in solid waste. E-waste consists of discarded refrigerators, TVs radios, Mobile phones, Air conditioners, computers and several other electronic gadgets that have reached end of life their or become a obsolete. . The major aim of the study is to examine the alter in mechanical properties of concrete with the addition of Electronic waste in concrete. It is found that the use of Electronic waste aggregates results in the formation of concrete. In this addition Coarse aggregate is replaced by $\mathrm{E}$ - waste from $0 \%$ to $15 \%$ then in these mix $5 \%$, $10 \%$ and $15 \%$. It is that utilization of this Electronic waste in concrete will reduce the requirement for conventional coarse aggregates there by resulting in used by natural resources.
\end{abstract}

Keywords: $E W, N A$, Concrete, Slump, Compressive Strength

\section{INTRODUCTION}

One of the new waste materials used in the concrete industry is recycled e-waste. For solving the disposal of large amount of recycled e-waste material, reuse of e-waste in concrete industry is considered as the most feasible application. In this present experiment work the coarse aggregates are partially replaced by e-waste in the proportion of $5 \%, 10 \%, \& 15 \%$, respectively. Electronics waste, commonly known as e-scrap and ewaste, is the trash we generate from surplus, broken and obsolete electronic devices and was collected from the local market.

\subsection{EXPERIMENTAL INVESTIGATION}

To compare the compressive strength of Recycled E-waste used as Coarse Aggregate for Constructional Concrete with the Conventional concrete.

To know its applications in construction industry

$>$ To reduce the pressure on naturally available materials by replacing it with recycled e- waste aggregate.

$>$ To compare the physical characteristics of natural aggregate with E-waste recycled aggregate.

$>$ To study the behavior of fresh and hardened concrete reinforced with e- waste coarse aggregate.

\section{MATERIALSANDMETHODS}

\subsection{MATERIALS}

The ordinary Portland cement of 43 grade was taken for the present investigation work. All possible contact with moisture was avoided while storing cement. Concrete mixes were prepared using locally available sand. Ordinary crushed stone with size $20 \mathrm{~mm}$ was used as coarse aggregate in concrete mixes. They generally possess all the essential 
qualities of a good stone showing very high crushing strength, low absorption value and least porosity. In general, water fit for drinking is taken for mixing the concrete.

E-waste was collected locally area in the form of long chips. Copper strips present at the bottom of waste were removed manually and broke into 4.75 to $20 \mathrm{~mm}$ size. Specific gravity and water absorption was tested for E-waste.

\begin{tabular}{|l|l|l|l|}
\hline Properties & $\begin{array}{l}\text { Fine } \\
\text { Aggrigate }\end{array}$ & $\begin{array}{l}\text { Coarse } \\
\text { Aggrigate }\end{array}$ & E-Waste \\
\hline $\begin{array}{l}\text { Specific } \\
\text { Gravity }\end{array}$ & 2.65 & 2.71 & 2.0 \\
\hline $\begin{array}{l}\text { Water } \\
\text { Absorpion(\%) }\end{array}$ & 1.3 & 0.06 & 0.3 \\
\hline Colour & Dark & Dark & $\begin{array}{l}\text { Dark,light } \\
\text { Green }\end{array}$ \\
\hline Shape & - & Angluar & Angluar \\
\hline
\end{tabular}

Table 1: Physical Properties of Aggregate and EWaste

\subsection{CONCRETE MIXES}

The mix was designed of $20 \mathrm{Mpa}$ was designed according to the Indian Standard code. Mix proportions were presented and Electronic waste was added to the concrete mix with a w/c ratio 0.50 .

The percentage of E-waste added by weight was 0,5 , $10 \& 15 \%$. Mix concrete and modified concrete with varying percentage of Electronic waste.

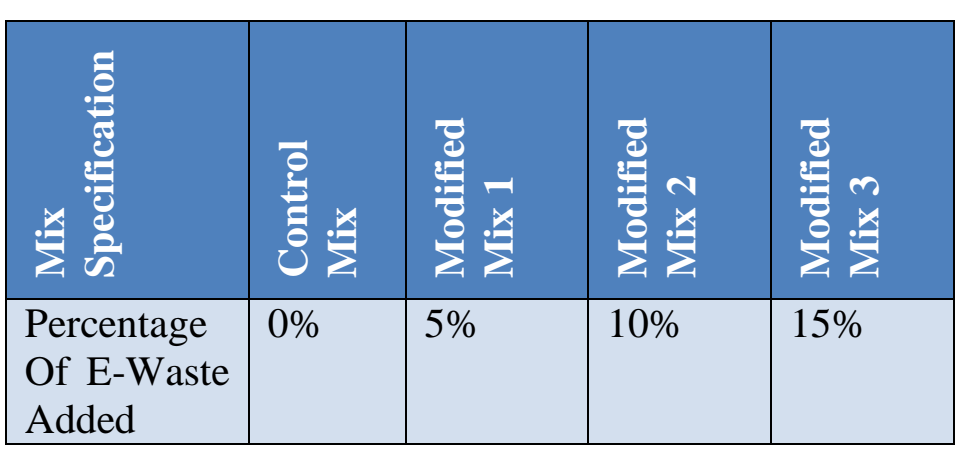

Table 2: Detals of Concrete Mix

\subsection{CURING}

Water curing is the most effective and useful method of curing. It gives the highest level of compressive strength. With these in mind, proper curing was done for specified days.

\section{EXPERIMENTAL PROCEDURE}

The purpose of testing, the concrete specimens were prepared for different mixes of concrete. Preparation of concrete aggregates, cement and Electronic waste was added. After the mixing, water was added and the mixing was continued until a mix was obtained. The concrete was then placed in to the moulds which were properly oiled and prepared. After placing of concrete in moulds,

For compressive strength test, cubes of size $15 \times 15 \times 15$ -cm-3 were cast. . Specimens thus prepared were demoulded after 24 hours of casting and doing curing in curing water tank. The dimensions of specimens used for the present study are listed in

\begin{tabular}{|l|l|}
\hline Test Detail & $\begin{array}{l}\text { Dimension Of The } \\
\text { Specimen }\end{array}$ \\
\hline Compressive Strength & Cube :150*150*150mm
\end{tabular}

Table3. Details of Test Specimens

\section{TESING OF MIX}

\subsection{SLUMP TEST}

Workability is a term associated with freshly prepared concrete. This can be defined as the ease with which concrete can mixed, placed, compacted and finished. Slump test is the most commonly used method of measuring 'workability' of concrete in a laboratory or at site of work. It is used to Vertical settlement of a standard cone of freshly prepared concrete is called 'slump test.

\section{Apparatus:}

Slump cone (bottom diameter $=20 \mathrm{~cm}$, top diameter $=$ $10 \mathrm{~cm}$, height=30 $\mathrm{cm}$ ), Weighing balance, tray, standard tamping rod, concrete mixer

\section{Materials used:}

Cement, stone chips (Coarse aggregate) and water

Concrete Mix: 1:1.5:3 (W/C=0.5). The ingredients are by weight. 


\begin{tabular}{|c|c|c|c|c|}
\hline $\begin{array}{c}\text { W/C } \\
\text { ratio }\end{array}$ & $\begin{array}{c}\text { Percentage of } \\
\text { plastic }\end{array}$ & $\begin{array}{c}\text { Height of } \\
\text { mould }\end{array}$ & $\begin{array}{c}\text { Height of } \\
\text { subsided }\end{array}$ & Slump \\
\hline replaced (\%) & H1 (mm) & $\begin{array}{c}\text { concrete H2 } \\
(\mathrm{mm})\end{array}$ & $\begin{array}{c}\text { H1-H2 (in } \\
\mathrm{mm})\end{array}$ \\
\hline 0.5 & 0 & 300 & 220 & 80 \\
\hline 0.5 & 10 & 300 & 225 & 75 \\
\hline 0.5 & 10 & 300 & 205 & 95 \\
\hline 0.5 & 15 & 300 & 214 & 86 \\
\hline
\end{tabular}

Table.4 Observation for Slump Test

\subsection{COMPRESSIVE STRENGTH TEST}

Presents the Compressive strength of concrete mixes with and without $\mathrm{E}$ waste aggregates, where $0 \%$ is $\mathrm{M} 0$ is Conventional Mix, M1 with E-waste of $5 \%$ of, M2 with $10 \%$ of E-waste and M3 with $15 \%$ of E-waste

\begin{tabular}{|l|l|l|}
\hline Mix & $\begin{array}{l}\text { Mix } \\
\text { Name }\end{array}$ & $\begin{array}{l}\text { 3 Days Strength } \\
(\mathbf{M p a})\end{array}$ \\
\hline M 20 & M0 & 15.36 \\
\hline M 20 \& replace 5\% & M1 & 16.87 \\
\hline M 20 \& replace 10\% & M2 & 18.93 \\
\hline M 20 \& replace 15\% & M3 & 15.32 \\
\hline
\end{tabular}

Table 5: 3 days compressive strength of conventional concrete and partially replaced with e-waste

\begin{tabular}{|c|c|c|}
\hline Mix & Mix Name & $\begin{array}{c}\text { 7 Days } \\
\text { Strength } \\
\text { (Mpa) }\end{array}$ \\
\hline M 20 & M0 & 19.55 \\
\hline M 20 \& Replace 5\% & M1 & 20.33 \\
\hline M 20 \& Replace 10\% & M2 & 22.21 \\
\hline M 20 \& Replace 15\% & M3 & 21.05 \\
\hline
\end{tabular}

Table 6: 7 days compressive strength of conventional concrete and partially replaces with e waste 
International Journal of Trend in Scientific Research and Development (IJTSRD) ISSN: 2456-6470

\begin{tabular}{|c|c|c|}
\hline Mix & $\begin{array}{c}\text { Mix } \\
\text { Name }\end{array}$ & $\begin{array}{l}28 \text { Days } \\
\text { Strength } \\
\text { (Mpa) }\end{array}$ \\
\hline M 20 & M0 & 21.00 \\
\hline M 20 \& replace $5 \%$ & M1 & 22.26 \\
\hline M 20 \& replace $10 \%$ & M2 & 28.42 \\
\hline M 20 \& replace $15 \%$ & M3 & 23.10 \\
\hline
\end{tabular}

Table 7: 28 days compressive strength of conventional concrete and partially replaces with e waste

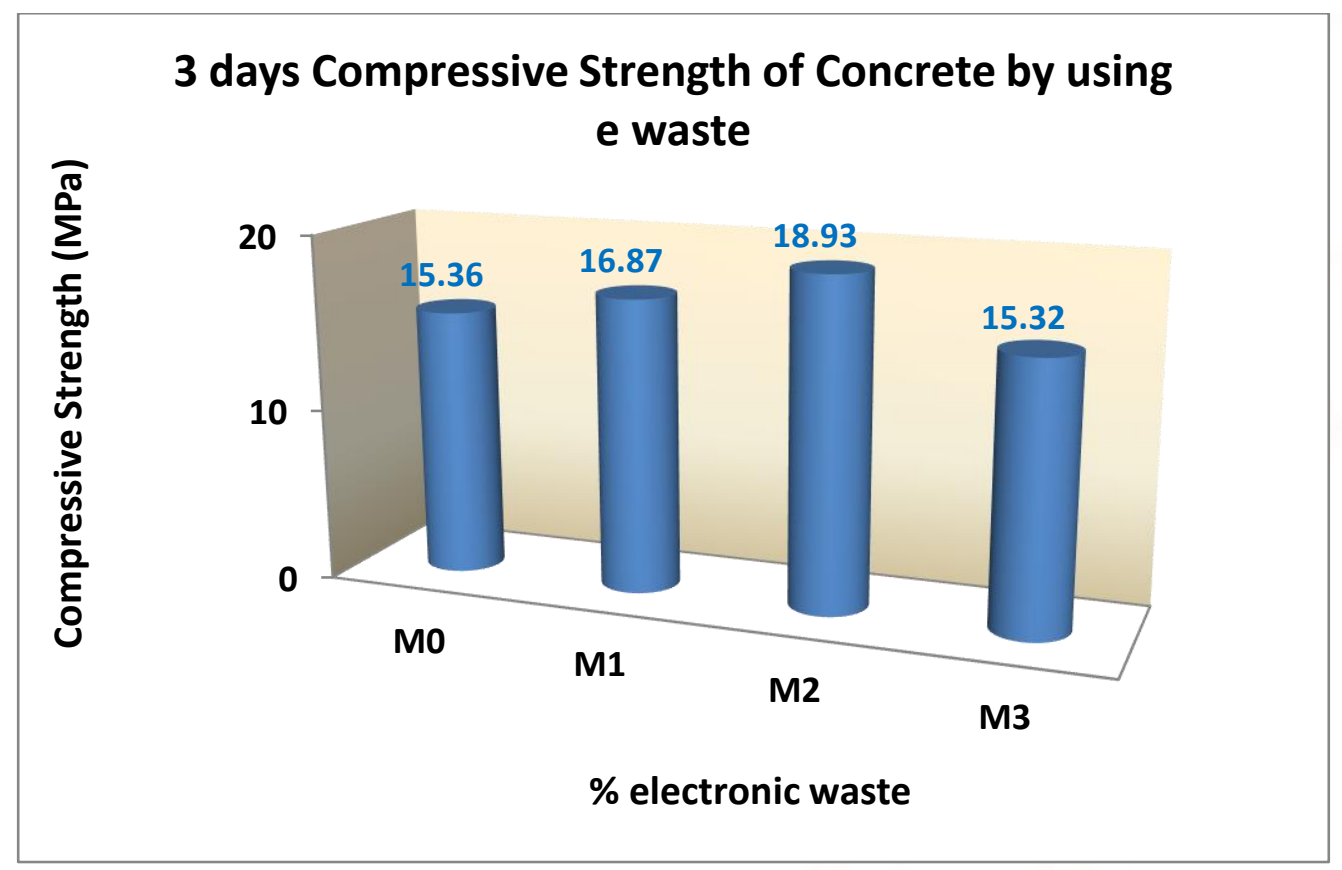

Figure 1:- 3 days compressive strength

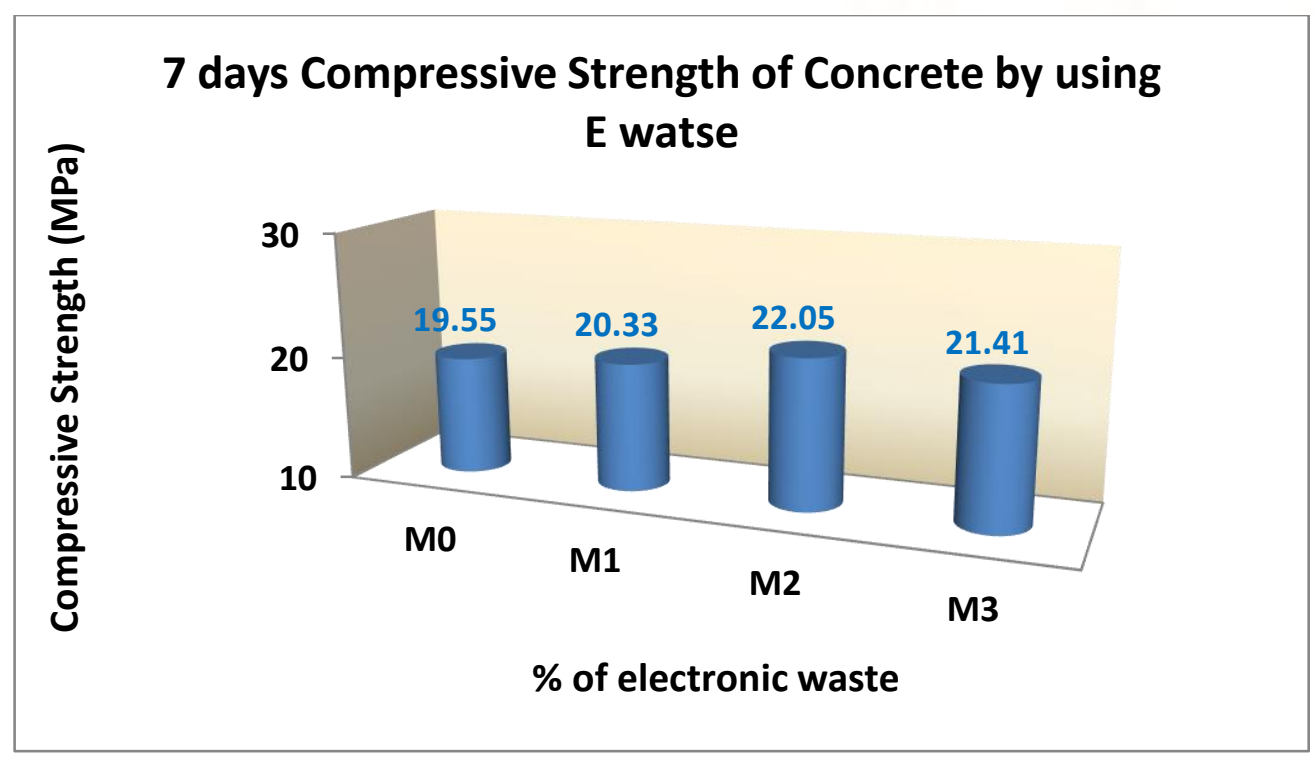

Figure 2:- 7 days compressive strength 


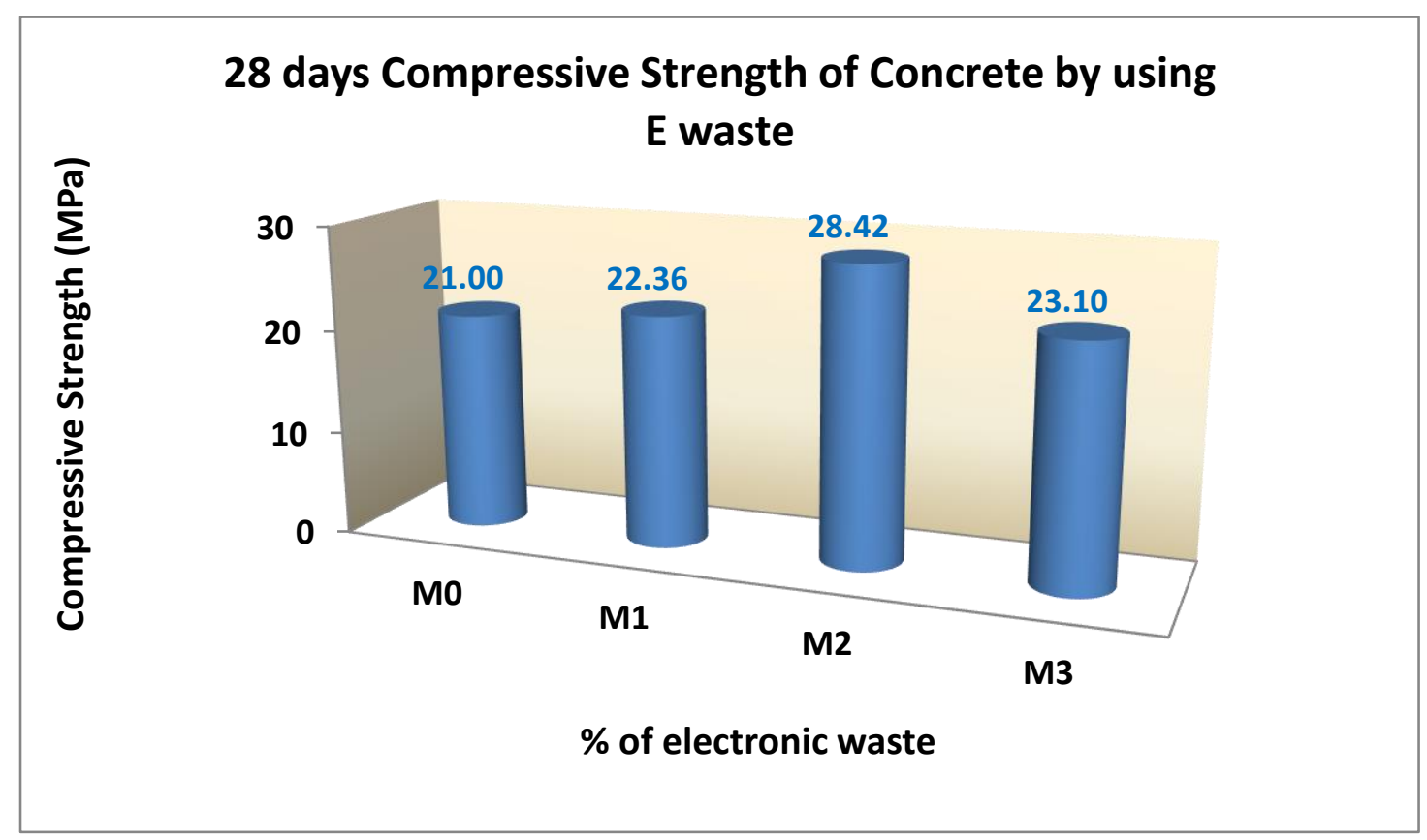

Figure 3:- 28 days compressive strength

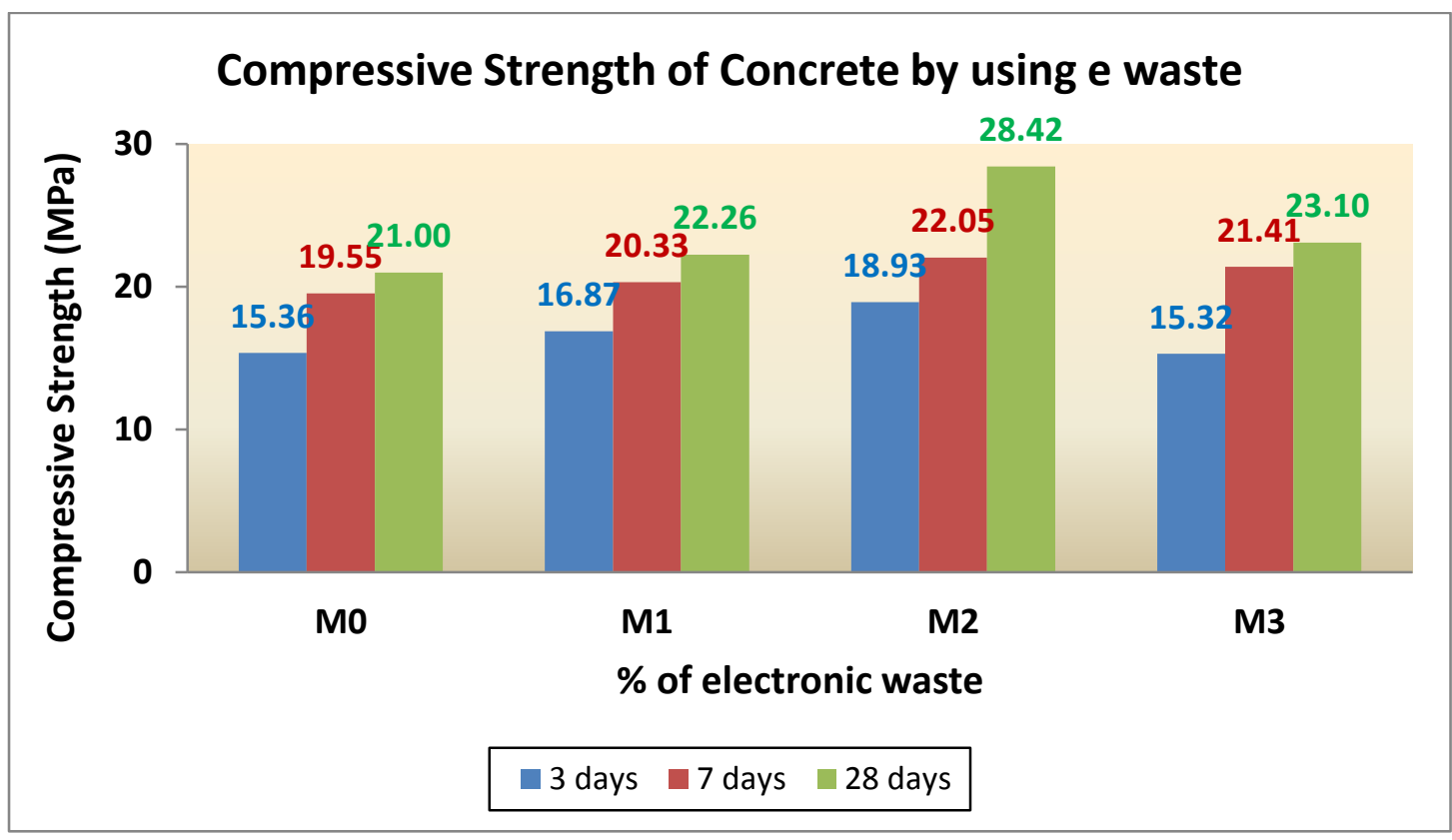

Figure 4:- Comparative compressive strength

\section{CONCLUSION}

The following conclusions are drawn with the current research work:

1) Using E- waste as coarse aggregate partially replacement in concrete, 28 days strength is found to marginally increase up to $10 \%$ replacement level.

2) It was observed that the optimum strength is 28.42 $\mathrm{MPa}$ at $10 \%$ replacement level of coarse aggregate with the E waste.
3) Due to e- waste, it proved to be very effective in assuring very good cohesiveness of mortar and concrete.

4) As compare to conventional concrete, on addition of electronic waste more than $10 \%$ its characteristic strength is decreased. So the electronic waste has been replaced by up to $10 \%$ by weight of aggregate without affecting the characteristic strength of M20 grade concrete. 
5) The best possible way of disposal of waste material like $\mathrm{E}$ waste can be done by using it in concrete, which will reduce environmental burden.

6) We have put forth a simple step to minimize the costs for construction with usage of electronic waste because it is freely and cheaply available.

7) We have also stepped into a realm of saving the environment from pollution by aggregate production; being our main objective as Civil Engineers.

\section{REFRENCES:}

1) Praveen Mathew, Shibi Varghese, Thomas Paul Recycled Plastics as Coarse Aggregate for Structural Concrete, IJIRSET, March 2013

2) Lakshmi, Nagan.S, Studies on Concrete containing E plastic waste,International Journal Of Environmental Sciences, 2010.

3) IS 10262 (2009): Guidelines for concrete mix design.

4) MS Shetty, Concrete Technology, Theory and Practice, Revised Edition, 2010

5) V. Kasselouri - Rigopoulou, S. Gavela, S. Kolias "Use Of Polymeric Wastes in The Concrete Production" Polymers in concrete: a vision for the 21st century, Cement \& Concrete Composites.

6) Tomas U. GanironJr "Effect of Thermoplastic as Fine Aggregate to Concrete Mixture" International Journal of Advanced Science and Technology, 2014.

7) S.P.Kale, H.I.Pathan "Recycling of Demolished Concrete and E-waste" International Journal of Science andResearch, 2013.

8) Salman Siddique, SikandarShakil, ShdabSddiqui"Scope of Utilisation of E-waste in Concrete" InternationalJournal of Advance Research in Science and Emerging Vol. No 4, Special Issue (01), March 2015. 